\title{
Enfermagem frente ao suicídio infanto-juvenil
}

\author{
Nursing in front of the child-youth suicide
}

Enfermería frente al suicidio niño-juventud

Júlia Góes de Menezes ${ }^{1 *}$, Suelen Suzy Gomes Baptista ${ }^{1}$, Graciana de Sousa Lopes.

\section{RESUMO}

Objetivo: Discutir os aspectos relacionados ao suicídio infanto-juvenil. Métodos: Trata-se de uma revisão integrativa da literatura com coleta de dados por meio de levantamento bibliográfico, os levantamentos de dados foram coletados nas bibliotecas virtuais LILACS, BVS e SCIELO, sendo inclusos artigos publicados nos últimos 10 anos de 2009 a 2019. Resultados: A partir da análise de conteúdo dos materiais coletados a fim de responder as questões de pesquisa, emergiram-se então as seguintes categorias: I) Fatores que levam a criança/adolescente ao suicídio; II) Ações que salvam vidas, que mostram a importância da família no reconhecimento dos fatores de risco e no tratamento da criança/adolescente que passa por ideação suicida ou que já tentou o suicídio, além de relatar meios de ajudar esse grupo e discutir o que leva o infanto-juvenil a cometer este ato. Considerações finais: $O$ suicídio afeta tanto quem comete $o$ ato quanto quem convive com o suicida.

Palavras-chave: Suicídio infantil, Suicídio, Comportamento suicida, Sentimentos, Riscos, Enfermagem.

\begin{abstract}
Objective: To discuss aspects related to child and youth suicide. Methods: It is an integrative literature review with data collection through bibliographic survey, data surveys were collected in the virtual libraries LILACS, BVS and SCIELO, including articles published in the last 10 years from 2009 to 2019. Results: From the content analysis of the collected materials in order to answer the research questions, the following categories emerged: I) Factors that lead the child / adolescent to suicide; II) Actions that save lives, that show the importance of the family in the recognition of risk factors and in the treatment of the child / adolescent who goes through suicidal ideation or who has already attempted suicide, in addition to reporting ways to help this group and discuss what leads children and adolescents to commit this act. Final Considerations: Suicide affects both those who commit the act and those who live with the suicide.
\end{abstract}

Keywords: Child suicide, Suicide, Suicidal behavior, Feelings, Risks, Nursing.

\section{RESUMEN}

Objetivo: discutir aspectos relacionados con el suicidio infantil y juvenil. Métodos: Es una revisión de literatura integradora con recolección de datos a través de levantamiento bibliográfico, se recolectaron levantamientos de datos en las bibliotecas virtuales LILACS, BVS y SCIELO, incluyendo artículos publicados en los últimos 10 años de 2009 a 2019. Resultados: A partir del análisis de contenido de los materiales recolectados para dar respuesta a las preguntas de la investigación, surgieron las siguientes categorías: I) Factores que llevan al niño / adolescente al suicidio; II) Acciones que salvan vidas, que muestren la

${ }^{1}$ Centro Universitário Faculdade Metropolitana de Manaus (CEUNI-FAMETRO), Manaus - AM.

*E-mail: julinhagoes_menezes@hotmail.com 
importancia de la familia en el reconocimiento de factores de riesgo y en el tratamiento del niño / adolescente que pasa por ideación suicida o que ya ha intentado suicidarse, además de relatar formas de ayudar a este colectivo y discutir qué lleva a los niños y adolescentes a cometer este acto. Consideraciones fnales: El suicidio afecta tanto a quienes cometen el acto como a quienes conviven con el suicidio.

Palabras clave: Suicidio infantil, Suicidio, Conducta suicida, Sentimientos, Riesgos, Enfermería.

\section{INTRODUÇÃO}

O suicídio é uma causa externa de autoviolência e autoagressão, realizado pelo próprio indivíduo ciente e com intenção de morrer, que se tornou um problema de saúde pública não só no Brasil, mas em todo o mundo, tornando-se um fenômeno universal, em que todos os anos cerca de 800 mil pessoas suicidam-se, já a tentativa de suicídio é todo ato de autoagressão que não leva a vítima a morte, ocorrendo em torno de 10 vezes mais que o próprio suicídio (VIDAL CEL e GONTIJO ED, 2013; WHO, 2014; D'ECA JUNIOR A, 2019; SOUZA VS, et al., 2011).

De acordo com o MDH (2019), os índices de suicídio são diferentes no mundo, sendo mais altos em países capitalistas avançados e nos de nível socioeducacional médio e baixo, sendo os homens os que mais cometem suicídio na fase adulta, e as mulheres na adolescência entre 15 e 19 anos, no entanto, a OMS apresenta em seus dados que o suicídio no mudo cresce conforme a idade, em particular nos países socioeconômico baixo e médio, estando o Japão em primeiro lugar nos índices de suicídio entre os países capitalistas avançados, já o Brasil, é o oitavo entre os países latinos, permanecendo entre os 29 em que mais crescem os casos de suicídio, sendo o Norte a região que apresenta maior crescimento.

Segundo Brasil (2015), em 2006 foi desenvolvido pelo Ministério da Saúde (MS) a "Estratégia Nacional de Prevenção do Suicídio", objetivando diminuir os danos e as altas taxas de suicídio e tentativas. Foram instituídas através da Portaria $n^{\circ} 1.856 / \mathrm{GM} / \mathrm{MS}$, de 14 de agosto de 2006, As "Diretrizes Nacionais de Prevenção do Suicídio", com a finalidade de desenvolver estudos identificar a prevalência de fatores de risco em populações vulneráveis. MDH (2019) diz que, no entanto, o Brasil, ainda é o oitavo entre os países latinos com maior índice de suicídio, permanecendo entre os 29 em que mais crescem os casos, sendo o Norte a região que apresenta maior crescimento, chegando a $77 \%$, o Nordeste chega a $51,7 \%$, e o Sudeste logo atrás com $35,8 \%$ de crescimento, sendo o Sul com 15,2\% e Centro-Oeste com 16,3\% as regiões com menor índice.

Para Salazar JMRS e Oliveira MFS (2015), devido ao mito da infância feliz, é difícil para os adultos verem as crianças como seres capazes de dar fim a própria vida, criando uma negação de aceitação da realidade, onde não se percebe a criança como um ser que também passa por situações e sentimentos não tão diferentes da vida adulta, seres que muitas vezes vivem uma fase nada tranquila, passando por frustrações e sofrimentos. Segundo Lemos MFL e Salles AMB (2015), o suicídio infantil pode ser resultado de sofrimento psíquico, decorrentes das nosologias clássicas como o autismo, sem descartar fatores ambientais, e as relações familiar e social.

De acordo com Who (2014), comportamento suicida, é uma pluralidade de comportamentos que ocorre de forma contínua e inclui a ideação suicida, planejamento do suicídio, tentativa de suicídio e a concretização do ato, sendo muitas vezes a depressão o principal motivo para o ato. Segundo Brito I (2011), o tratamento da depressão deve ser planejado entre a equipe, família e o paciente, envolvendo a psicoterapia, medicação e os próprios familiares, levando em consideração que a psicoterapia é um tratamento de primeira linha que, associada a terapêutica medicamentosa pode solucionar os sintomas e o funcionamento intrapessoal e a relação social, familiar e escolar do utente.

Brito I (2011) também diz que a fase da adolescência é um período peculiar com inúmeras transformações que vai desde as mudanças físicas, psíquicas, afetivas e sociais, onde a puberdade traz alterações morfológicas e hormonais, que impõem novas formas de sentir, pensar e agir, principalmente em relação ao seu próprio corpo e especialmente na relação com os pais, pois nesta fase surgem os conflitos de dependência e autonomia. 
De acordo com Lobin L (2012) citado por Resende C (2013), é estimado que a depressão ocorre em cerca de $2 \%$ das crianças sem predomínio de gênero, aumentando de $4-8 \%$ na adolescência, principalmente entre as meninas, que apresentam 4 vezes mais o risco de desenvolver a doença do que os meninos. Os adolescentes apresentam sintomas típicos e semelhantes aos apresentados por adultos como: sentimentos de desesperança, desinteresse, apatia, culpa, perda de energia, hipersonia, lentidão psicomotora, dificuldade de concentração, alterações de apetite e peso, isolamento, baixa autoestima, fadiga e ideação suicida, além desses, apresentam cefaléia e dor abdominal, e no lugar de tristeza se mostram irritadiços e explosivos, bem diferente dos adultos, podendo persistir por duas semanas ou mais, seguido de sofrimento relevante ou prejuízo social, sendo estes sintomas moderados ou severos e recorrentes, que levam o adolescente a passar pela ideação, tentativa e o ato suicida (DE LIMA A, et al., 2013; CAMPOS JR, et al., 2014).

Segundo Thapar A, et al. (2012), os fatores de risco da depressão na adolescência estão agrupados em três categorias: fatores individuais, resultantes dos aspectos biológicos e psicodinâmicos como o temperamento e a personalidade que influenciam, na forma de enfrentamento das dificuldades; fatores de risco familiares, decorrentes da genética em que um dos pais apresentam ou apresentaram quadro depressivo, e através do impacto materno no cuidado durante a infância; fatores de risco psicossociais, podendo ser agudos, como perdas, doenças e acidentes, ou crônicos como conflito familiar durante toda a infância, bullying e violência.

Para Erse MPQA, et al. (2016), a escola é como um ambiente saudável e promotor de saúde mental, portanto, é importante que sejam adotados meios de intervenções que visem prevenção e detecção precoce, para que assim, possam servir de referência para os serviços de saúde mental, ajudando a desenvolver competências pessoais e individuais positivas e resiliência, objetivando combater os fatores de risco, é importante reforçar a inclusão de profissionais de saúde mental no ambiente escolar, e investir na formação e treino desses profissionais, além de orientar, alertar e ensinar professores, pais e estudantes, para que assim possam ser capazes de perceber, identificar e intervir nos sinais e sintomas da depressão e comportamentos suicidas.

De acordo com Rosa M (2010) citado por Feitosa MP, et al. (2011), a família representa um importante papel na vida do adolescente que sofre depressão, pois é onde ele pode buscar apoio, ajuda e consolo, por isso, entender todas as fases da doença permite que o deprimido seja melhor auxiliado, infelizmente, a maioria dos familiares não possuem conhecimento sobre a patologia e acabam causando sofrimento para ambos, por não entenderem que o comportamento da pessoa está relacionado a doença e não a sua própria vontade.

Segundo Erse MPQA, et al. (2016), é importante incluir as famílias e fortalecer as redes de apoio no trabalho tanto para o tratamento quanto para as intervenções de prevenção para adolescentes, pois as relações saudáveis familiares, de amizade ou amorosas assumem papeis protetores para a depressão, sendo a compreensão e conhecimento por parte da família é um dos principais meios de proteger o deprimido.

Assim, o presente estudo aproxima-se do universo dos sobreviventes suicidas partindo do seguinte questionamento: $O$ que leva a criança e ao adolescente a tentarem/cometerem suicídio? Neste contexto, o objetivo deste estudo é discutir os aspectos relacionados ao suicídio infanto-juvenil. Os objetivos específicos se caracterizam em descrever os fatores de risco relacionados ao suicídio infanto-juvenil; discutir sobre as condutas de prevenção do suicídio infanto-juvenil.

\section{MÉTODOS}

Trata-se de uma revisão integrativa da literatura com coleta de dados por meio de levantamento bibliográfico, a coleta dos artigos foi realizada nas bases, Biblioteca Cientifica Eletrônica Online (SCIELO), Literatura Latino-Americana e do Caribe em Ciências da Saúde (LILACS) e Portal Regional da Biblioteca Virtual em Saúde (BIREME), utilizando-se os seguintes descritores: "suicídio infantil", "suicídio", "comportamento suicida", "sentimentos", "riscos" e "enfermagem". A investigação foi realizada a partir da temática Enfermagem Frente ao Suicídio Infantil, considerando artigos publicados entre os anos de 2009 a 2019. 
Foram usados como critérios de elegibilidade: artigos que retratassem a temática dos resumos pertinentes aos objetivos; artigos publicados e indexados nos referidos bancos de dados nos últimos dez anos; artigos disponíveis para download; artigos escritos em língua portuguesa, inglesa e espanhola; artigos completos e originais (Figura 1).

Como critérios de inelegibilidade foram usados: duplicatas; livros, mídias e reportagens; monografias, teses e dissertações; artigos não disponíveis para download; resumos com conteúdo fora da temática objetivada; artigos que não respondiam as questões de pesquisa (Figura 1). Os artigos foram lidos e selecionados de acordo com os critérios de elegibilidade e inelegibilidade a partir dos títulos, posteriormente foi realizada a análise de resumos e por último foram lidos na integra.

Figura 1 - Fluxograma dos critérios de elegibilidade e inelegibilidade de pesquisa.

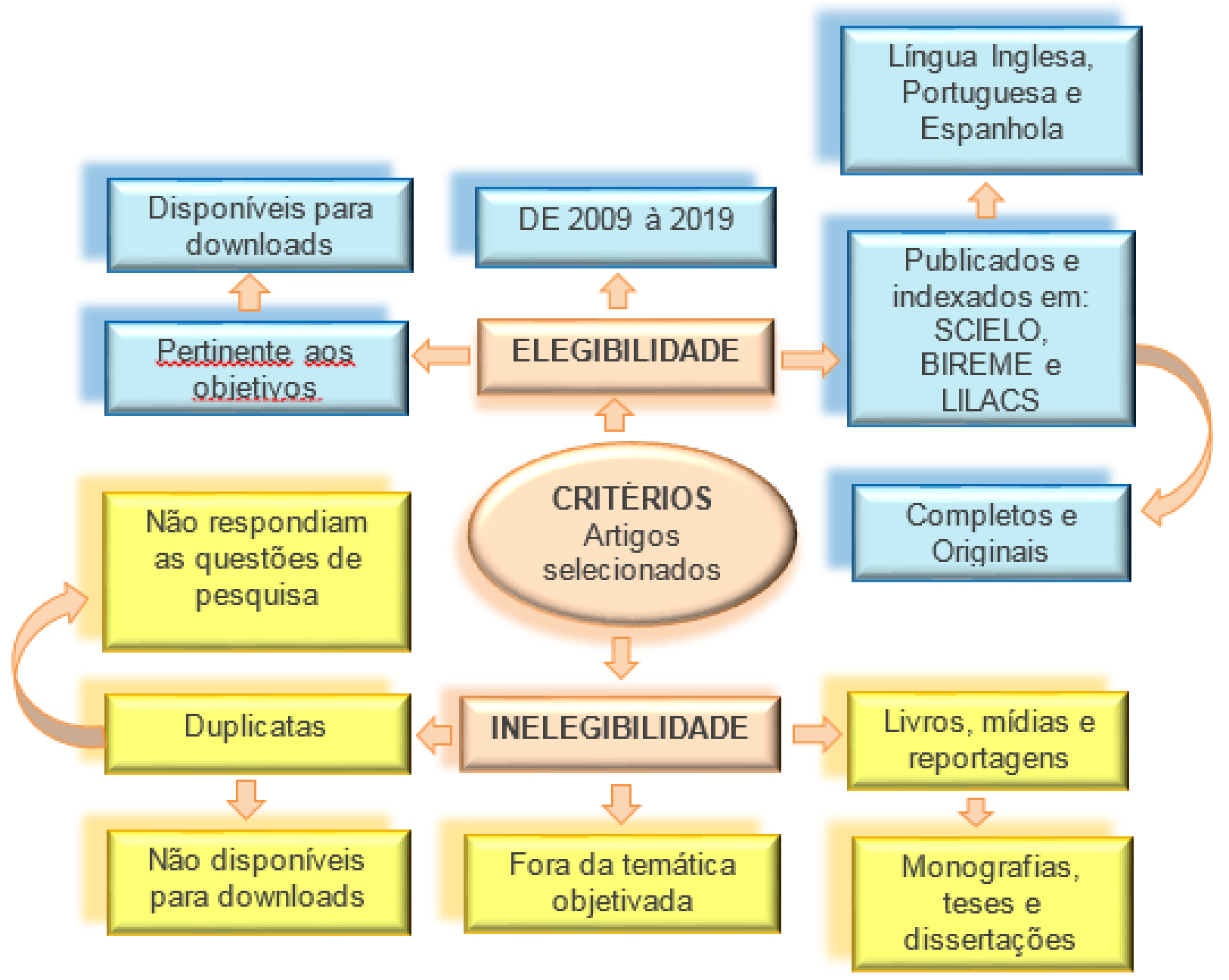

Fonte: Menezes JG, et al., 2020.

\section{RESULTADOS E DISCUSSÃO}

Na primeira etapa da pesquisa foram encontrados 43 artigos que foram analisados de acordo com os critérios de inclusão e exclusão, onde foram excluídos todas as duplicatas e todos as monografias e dissertações, na terceira etapa todos os artigos foram lidos e relidos, restando 16 artigos entre os anos de 2009 a 2019. Emergiram-se então as seguintes categorias: I) Fatores que levam a criança/adolescente ao suicídio; II) Ações que salvam vidas (Quadro 1). 
Quadro 1 - Descrição dos artigos selecionados.

\begin{tabular}{|c|c|c|c|}
\hline Autores / Ano & Idioma & Objetivo & Resultados \\
\hline De Souza ALP, et al. (2019) & Inglês & $\begin{array}{l}\text { Caracterizar o comportamento suicida em crianças } \\
\text { de } 5 \text { a } 12 \text { anos diagnosticados com depressão. }\end{array}$ & $\begin{array}{l}\text { Condições de vida precoce como a morte dos pais é } \\
\text { considerado risco de suicídio em três países segundo } \\
\text { um estudo. }\end{array}$ \\
\hline Zelaya De Migliorisi L, et al. (2012). & Espanhol & $\begin{array}{l}\text { Relatar as características clínica e epidemiológica } \\
\text { dos infanto-juvenis que cometem a tentativa de } \\
\text { suicídio e são atendidos no Hospital Geral de } \\
\text { Pediatria Niños de Acosta Ñu na cidade de San } \\
\text { Lorenzo, Paraguai }\end{array}$ & $\begin{array}{l}\text { As meninas de } 15 \text { a } 19 \text { são mais propensas a realizar o } \\
\text { ato suicida, geralmente são adolescentes que sofreram } \\
\text { violência e abusos desde a infância e os principais } \\
\text { agressores são os pais. }\end{array}$ \\
\hline Sousa GS, et al. (2017). & Português & $\begin{array}{l}\text { Analisar a literatura específica sobre suicídio em } \\
\text { crianças de até } 14 \text { anos. }\end{array}$ & $\begin{array}{l}\text { Apesar de poucos estudos sobre o comportamento } \\
\text { suicida, foi possível perceber que as crianças } \\
\text { expressam menos a vontade de morrer do que os } \\
\text { adolescentes, e o enforcamento é o método mais } \\
\text { usado. }\end{array}$ \\
\hline Guerrero-Martinez LF (2016). & Espanhol & $\begin{array}{l}\text { Mostrar características clínicas da tentativa de } \\
\text { suicídio infantil sob o olhar do conceito de } \\
\text { violência no grupo feminino. }\end{array}$ & $\begin{array}{l}\text { Um fator de risco para o suicídio na adolescência é a } \\
\text { violência, seja através de discussões com familiares e } \\
\text { parentes, no relacionamento amoroso, físico, verbal ou } \\
\text { psicológico. }\end{array}$ \\
\hline Barros PDQ, et al. (2017). & Português & $\begin{array}{l}\text { Identificar a relação entre a ideação suicida e o } \\
\text { consumo abusivo de drogas por adolescentes. }\end{array}$ & $\begin{array}{l}\text { Adolescentes buscam alegria e esquecer situações } \\
\text { difíceis através do uso de drogas, com intenção de } \\
\text { tornar a situação do momento mais fácil. }\end{array}$ \\
\hline Zelaya De miglioirsi L, et al. (2009). & Português & $\begin{array}{l}\text { Descrever as características epidemiológicas, os } \\
\text { motivos das consultas mais frequentes e } \\
\text { diagnósticos associados ao abuso infantil, } \\
\text { ocorridos em julho de } 2001 \text { a setembro de } 2009 \text {. }\end{array}$ & $\begin{array}{l}\text { O abuso infantil geralmente parte dos próprios pais, } \\
\text { sendo o abandono o abuso mais frequente, seguido do } \\
\text { abuso sexual e violência doméstica. }\end{array}$ \\
\hline Diehl A e Laranjeira R (2009). & Inglês & $\begin{array}{l}\text { Relatar a associação do consumo agudo ou } \\
\text { dependência de drogas nas tentativas de suicidio } \\
\text { atendidas em um pronto-socorro. }\end{array}$ & $\begin{array}{l}\text { Neste estudo, os adolescentes que tentaram suicídio } \\
\text { haviam usado drogas } 6 \text { horas antes da tentativa, e } \\
\text { todos os dependentes já tentaram concretizar o ato } \\
\text { suicida pelo menos uma vez. }\end{array}$ \\
\hline Ribeiro NM, et al. (2018). & Inglês & $\begin{array}{l}\text { Realizar uma análise epidemiológica nos bancos de } \\
\text { dados do Sistema de Informação de Mortalidade e } \\
\text { Sistema de Informação de Agravos de Notificação } \\
\text { dos casos de tentativas e do próprio suicídio. }\end{array}$ & $\begin{array}{l}\text { As mulheres tentam mais suicídio que os homens, no } \\
\text { entanto, adolescentes de } 15 \text { a } 19 \text { anos de ambos os } \\
\text { sexos são os que mais tentam o suicídio. }\end{array}$ \\
\hline
\end{tabular}




\begin{tabular}{|c|c|c|c|}
\hline Autores / Ano & Idioma & Objetivo & Resultados \\
\hline Bertolote JM, et al. (2010). & Português & $\begin{array}{l}\text { Auxiliar os profissionais de saúde para a } \\
\text { identificação dos fatores de risco e no manejo do } \\
\text { paciente em risco através da anamnese. }\end{array}$ & $\begin{array}{l}\text { O profissional não deve julgar a atitude do paciente, } \\
\text { deixando de lado seus preconceitos e crenças, } \\
\text { passando a olhar apenas para o paciente, com objetivo } \\
\text { de entender e perceber sinais de riscos. }\end{array}$ \\
\hline Barbosa AKL, et al. (2016) & Português & $\begin{array}{l}\text { Analisar a relação do bullying com o suicídio, } \\
\text { estudar outros fatores e analisar a relação entre } \\
\text { bullying, autoestima e suicídio na adolescência. }\end{array}$ & $\begin{array}{l}\text { Existe uma ligação entre o bullying e o suicídio, pois na } \\
\text { maioria das vezes, o suicida já estava cansado de } \\
\text { suportar bullying e busca a morte como solução para se } \\
\text { livrar da pressão exercida pelo crime que vem sofrendo. }\end{array}$ \\
\hline Leite FÁA e Alves MAG (2016) & Português & $\begin{array}{l}\text { Verificar o quantitativo de casos de tentativa de } \\
\text { suicídio entre adolescentes no municipio de } \\
\text { Matozinhos, Minas Gerais, de } 2008 \text { a 2012, e } \\
\text { compreender os fatores de risco. }\end{array}$ & $\begin{array}{l}\text { Adolescentes que vivem em uma família sem } \\
\text { afetividade, que sofrem abandonos ou neligencias, } \\
\text { carregam sentimentos de solidão, e acabam por } \\
\text { desenvolver os desejos de morte. }\end{array}$ \\
\hline Kitagawa T, et al. (2019) & Português & $\begin{array}{l}\text { Relatar internações em um hospital de ensino que } \\
\text { ocorreram de janeiro de } 2011 \text { a dezembro de } 2015 \\
\text { por tentativas de suicídio por meio de agentes } \\
\text { químicos. }\end{array}$ & $\begin{array}{l}\text { Pessoas que tentam o suicídio várias vezes precisam de } \\
\text { intervenções com urgência, para que o ato não seja } \\
\text { consumado, além disso, a estrutura familiar pode afetar } \\
\text { de forma positiva ou negativa na prevenção do suicídio. }\end{array}$ \\
\hline Batista MD, et al. (2018) & Português & $\begin{array}{l}\text { Despertar atenção para o comportamento suicida } \\
\text { para evitar a tentativa de suicídio. }\end{array}$ & $\begin{array}{l}\text { O vínculo afetivo e a sensação de pertencer a um lugar } \\
\text { ou grupo permite que o sujeito queira ser tratado e se } \\
\text { conscientize da sua situação em que está. }\end{array}$ \\
\hline Kovács MJ e Hwang E (2019) & Português & $\begin{array}{l}\text { Despertar a visão para o suicídio por contágio e } \\
\text { ampliar uma discussão a respeito dos múltiplos } \\
\text { componentes. }\end{array}$ & $\begin{array}{l}\text { A mídia deve atentar-se na forma de passar o suicídio, } \\
\text { para que não o transforme em espetáculo e sim como } \\
\text { um problema de saúde grave que pode ser evitado. }\end{array}$ \\
\hline Koch DB e De Oliveira PRM (2015) & Português & $\begin{array}{l}\text { Apresentar as políticas públicas relacionadas ao } \\
\text { suicídio e observar quais politicas afeta essa área e } \\
\text { como vêm trabalhando na prevenção no mundo, } \\
\text { para que seja permitido a criação de políticas } \\
\text { públicas regionalizadas. }\end{array}$ & $\begin{array}{l}\text { As políticas públicas buscam muitos meios de prevenir } \\
\text { o suicídio, podendo ser através da imprensa, escolas e } \\
\text { aperfeiçoamento de profissionais. }\end{array}$ \\
\hline $\begin{array}{l}\text { De Jesus Bezerra J e Da Silva FV } \\
\text { (2019) }\end{array}$ & Português & $\begin{array}{l}\text { Discutir a respeito do biopoder e a biopolítica e } \\
\text { analisar as estratégias nas materialidades das } \\
\text { campanhas. }\end{array}$ & $\begin{array}{l}\text { A campanha busca alertar a sociedade em geral, tanto } \\
\text { autocidas quanto os que não passam por esse tipo de } \\
\text { sofrimento, através de informações que incentivam a } \\
\text { busca por ajuda. }\end{array}$ \\
\hline
\end{tabular}




\section{Categoria I: Fatores que levam a criança/adolescente ao suicídio}

Crianças que apresentam comportamento suicida apresentam como fatores de risco para o suicídio problemas pessoais como violência física ou sexual, uso de álcool e drogas, e distúrbios da sexualidade; problemas familiares, por exemplo, a morte de um familiar, conflito com a família, abandono por parte da família e histórico de doença psiquiátrica na família; e problemas escolares, destacando-se o baixo rendimento ou atraso escolar, abandono escolar e o bullyng (DE SOUZA ALP, et al., 2019; SOUSA GS, et al., 2017).

Barros PDQ, et al. (2017), relata que ao usar drogas, os adolescentes com ideação suicida buscam esquecer seus problemas e dificuldades, tentando encontrar alegria e aceitação social de alguma forma, entre esses usuários de substâncias químicas, é comum as tentativas de suicídio ou ideação suicida, e muitos apresentam impulsividade e agressividade, principalmente os que usam drogas injetáveis (DIEHL A e LARANJEIRA R, 2009).

Guerrero-Martinez LF (2016), afirma que a violência sexual, doméstica e abuso sexual afeta principalmente as mulheres adolescentes, levando-as a cometer suicídio. O suicídio na adolescência está associado a vários tipos de abusos sofridos na infância, com destaque a negligência associada ou não a violência doméstica, sendo os próprios pais os agressores, que expõem os filhos a lares abusivos e violentos (ZELAYA DE MIGLIOIRSI L, et al., 2009 e ZELAYA DE MIGLIORISI L, et al., 2012).

A falta de vínculo afetivo e a relação instável com a família e a sociedade geram violência intrafamiliar, levando o suicida a autoagressão, a falta de comunicação entre pais e filhos, e a falta de apoio induzem conflitos familiares que por sua vez, apresentam-se como fatores de risco para a ideação e 0 ato suicida (LEITE FÁA e ALVES MAG, 2016; KITAGAWA T, et al., 2019).

Barbosa AKL, et al. (2016), relata em seu estudo que o bullyng é crime e um forte fator para o suicídio infanto-juvenil, e envolve três atores, o autor, a vítima e a testemunha, ocorrendo de forma direta ou indireta, e ocorrem em todos os lugares, principalmente na escola, causa traumas na vida do indivíduo que sofre 0 ato, afeta a autoestima e leva ao suicídio, outro lugar com grande impacto de bullying é a internet, onde o ato é conhecido como cyberbullying, que ocorre por meio das redes sociais, onde a imagem da vítima é exposta através de publicações postadas de um aparelho eletrônico, com intenção de humilhar e difamar a vítima.

Segundo Maldonado MT (2011), no bullying há ataques repetitivos, podendo ser verbal ou agressivo, frente a frente com a vítima, no cyberbullying o ataque dura por muito tempo, através de mensagens, fotos ou filmagens constrangedoras, estando o autor na maioria das vezes oculto, sendo geralmente alguém que já foi próximo, e o que torna o cyberbullying pior e mais aterrorizante do que o bullying é a propagação, de maneira muito rápida o conteúdo divulgado alcança pessoas e lugares de todos os cantos, levando na pessoa a uma vergonha fatal, desesperada pela humilhação esse indivíduo busca no suicídio o fim da dor emocional.

Em seu estudo De Oliveira Abreu T e Souza MB (2017), dizem que a internet traz facilidade, no entanto, devido as inúmeras redes sociais, a criança e o adolescente já não vivem mais estas fases como antes, acabam por se exporem de várias formas sexuais, chegando a sofrer conflitos com a própria imagem e com a sua vida, além disso, as informações disponibilizadas pela internet nem sempre possuem verdades, mas sim conteúdos maldosos, agressivos e até criminosos, como vídeos e textos ensinando que incentivam as práticas suicidas.

Luxton DD, et al. (2012), afirmam que as redes sociais, sites e blogs também podem ser ferramentas para prevenir o suicídio, pois permite conexão entre indivíduos que passaram por situações semelhantes, ampliando conhecimento e conscientização a respeito das linhas de ajuda online, no Facebook por exemplo, pode-se encontrar páginas com informações sobre os riscos de suicídio que alertam os seguidores, links de sites que funcionam como linhas diretas são postados no Twitter e no Blogger, o YouTube disponibiliza vários vídeos e anúncios de combate ao suicídio, o próprio Google, ao usar palavras chave relacionadas a ideação suicida, exibe mensagens e links de sites e outras mídias que combatem o suicídio. 


\section{Categoria II: Ações que salvam vidas}

Para Batista MD, et al. (2018), o ato suicida necessita de atenção absoluta para que o índice de mortalidade pare de subir, este tipo de morte que pode ser prevenida precisa de foco e construção de técnicas que busquem evitar o suicídio, esses métodos precisam permitir o enfrentamento de dificuldades por parte do indivíduo, de forma que consigam solucionar suas dores emocionais, e para isso, deve haver iniciativa da sociedade, família e profissional em realizar ações que objetivem reconhecer fatores de risco e preservar a saúde mental desse sujeito, além de proporcionar qualidade de vida.

De acordo com Bertolote JM, et al. (2010), as intervenções de prevenção do suicídio devem ser elaboradas conforme avaliação sistemática do risco de suicídio apresentado pelo indivíduo, e de acordo com as condições sociais, familiares, pessoal e cultural do paciente, necessitando que cada fator de risco seja analisado de forma minuciosa, portanto, ao ganhar a confiança do sujeito, o enfermeiro deve realizar uma abordagem clara, afetiva e sem julgamentos, analisando pensamentos e comportamentos suicidas e atentando-se para a intensidade, frequência e persistência, para que possa ajudar e encaixar o autocida em uma rede de apoio e encaminhar para apoio psicossocial.

De acordo com Ribeiro NM, et al. (2018), é importante que haja uma conexão entre a porta de entrada da saúde ESF/NASF e a saúde mental, pois através do vínculo estabelecido entre a equipe multiprofissional e o sujeito, por meio da identificação dos problemas, pode-se identificar sinais de comportamento suicida, prevenir as tentativas e o próprio suicídio, e minimizar os danos e impactos do ato suicida, o CAPS, acompanha constantemente indivíduos autocidas, por prestar assistência a pessoas em crise e manter aproximação por longo prazo, a equipe pode intervir de forma eficaz na tentativa do suicídio, o enfermeiro, através da escuta, pode perceber angústias e a necessidade de acompanhamento domiciliar ou encaminhamento para profissionais especialistas.

Segundo Heck RM, et al. (2012), os CAPSs oferecem ajuda e apoio ao usuário que passa por autoviolência, buscando ligar-se a setores e sistemas diversificados com intuito de prestar acolhimento e oferecer assistência multidisciplinar tanto para o indivíduo quanto para a família, levando em consideração suas condições de vida e estimulando a participação dos envolvidos em todo o plano de ação para combater o suicídio e a automutilação.

De acordo com Batista MD, et al. (2018), em agosto de 2006 foi divulgado as Diretrizes Brasileiras para um Plano Nacional de Prevenção do Suicídio, com ações que inclui a melhora da qualidade de vida, ações que alertem os problemas envolvidos ao suicídio, o incentivo de novas pesquisas, capacitação dos profissionais, entre outras que visam prevenir as condutas suicidas, entretanto, são ações que ainda precisam ser desenvolvidas.

De acordo com Koch DB e De Oliveira PRM (2015), as políticas públicas apresentam eficácia em relação a fatores de risco coletivos na sociedade, pois os programas de prevenção podem ocorrer de várias maneiras, entre elas pode-se destacar o controle e monitoramento ao acesso de meios (pontes, passarelas e armas) usados para cometer o suicídio, campanhas em mídias (imprensa e redes sociais), campanhas em escolas e os centros de auxilio as crises (linhas diretas, hotlines).

Para Kovács MJ e Hwang E (2019), a reportagem é um meio de agir para prevenir o suicídio com grande eficácia, pois permite discussões e indicações de meios e locais para ajudar leitores, ouvintes e telespectadores que acompanham a reportagem e acabam refletindo sobre a temática, na reportagem o jornalista pode conscientizar a sociedade através de informações e esclarecimentos, buscando elevar a cobertura de suicídios para evitar equívocos e quebrar tabus.

Em seu estudo Blatt MR (2019) afirma que, a internet pode ser usada de maneira positiva no combate ao suicídio, através das redes sociais pode-se ver conteúdos com informações de alerta aos riscos de suicídio, orientações para que esses riscos possam ser percebidos por quem convive com alguém que faz parte desse grupo, encontramos também campanhas que objetivam promover saúde mental e qualidade de vida para 0 indivíduo, além de informar que existem meios de ajuda nos momentos de crise. 
De Jesus Bezerra J e Da Silva FV (2019), relatam que a campanha do Setembro Amarelo é uma estratégia que serve de alerta para toda a população, para que se atentem na gravidade da situação, e para que toda a sociedade esteja informada e saiba identificar um indivíduo com potencial suicida, também passa informação ao próprio suicida, de que existem meios, instituições e profissionais que podem ajudar a superar o momento de crise, objetivando combater o ato suicida e valorizar a vida, é uma campanha que envolve o Estado, várias instituições e unidades com um único foco "a vida".

\section{CONSIDERAÇÕES FINAIS}

O suicídio é um feito de autoviolência e autodestruição que causa uma série de sentimentos tanto em quem comete o ato, quanto em quem convive com o indivíduo em crise, no entanto, para ajudar o autocida é necessário respeito, ética e empatia, deixar de lado crenças e mitos, é importante a conscientização de todos, parar de pensar que é apenas uma fase ou um meio de chamar atenção por nada, a tentativa de suicídio deve ser vista como um pedido desesperado de socorro, é um chamar atenção para a dor e angustia que consome todo o ser, uma doença que cega a própria razão, sendo assim, fica claro a necessidade de mais políticas públicas que envolvam a família e que aproxime pais e filhos, sendo assim, é importante novos estudos sobre está temática.

\section{REFERÊNCIAS}

1. BARBOSA AKL, et al. Bullying e sua relação com o suicídio na adolescência. Id on Line Revista de psicologia, 2016; 10(31): 202-220.

2. BARROS PDQ, et al. Associação entre o consumo de drogas e a ideação suicida em adolescentes. Mental, Barbacena, 2017; 11(21): 304-320.

3. BATISTA MD, et al. Suicídio em jovens e adolescentes: uma revisão acerca do comportamento suicida, sua principal causa e considerações sobre as formas de prevenção. ID on line REVISTA DE PSICOLOGIA, 2018; 12(40): 705-719.

4. BERTOLOTE JM, et al. Detecção do risco de suicídio nos serviços de urgências psiquiátricas. Rev. Bras. Psychiatr.2010; 32(2): 87-95.

5. BLATT MR. A RELEVÂNCIA DAS REDES SOCIAIS NA PREVENÇÃO AO SUICÍDIO.Revista da Saúde da AJES, 2019; 5(10).

6. BRASIL. MINISTÉRIO DA SAÚDE. Estratégia Nacional de Prevenção ao Suicídio.2015.

7. BRITO I. Ansiedade e depressão na adolescência. Revista Portuguesa de Clínica Geral, 2011; 27(2): $208-214$.

8. CAMPOS JR, et al. Depressão na adolescência: habilidades sociais e variáveis sociodemográficas como fatores de risco / proteção. Estudos e Pesquisas em Psicologia, 2014; 14(2): 408-428.

9. D'ECA JUNIOR A, et al. Mortalidade por suicídio na população brasileira, 1996-2015: qual é a tendência predominante? Cad. saúde colet., 2019; 27(1): 20-24.

10. DE JESUS BEZERRA J, DA SILVA FV. As cores da vida: Estratégias biopolíticas nas campanhas setembro amarelo, outubro rosa e novembro azul. Miguilim-Revista Eletrônica do Netlli, 2019; 8(2): 728-741.

11. DE LIMA A, et al. Intensidade de sintomas depressivos em adolescentes através da escala de depressão de Beck (BDI-II). Boletim Academia Paulista de Psicologia, 2013; 33(85): 354-372.

12. DE OLIVEIRA ABREU T, SOUZA MB. A influência da internet nos adolescentes com ações suicidas. 2017.

13. DE SOUZA ALP, et al. Characterization of suicidal behavior among children in a depressive episode: case series study. Trends Psychiatry Psychother., 2019; 41(4): 394-400.

14. DIEHL A, LARANJEIRA R. Tentativas de suicídio e uso de substâncias em amostra de pronto-socorro. J. bras. psiquiatr., 2009; 58(2): 86-91.

15. ERSE MPQA, et al. Depressão em adolescentes em meio escolar: Projeto+contigo. Rev. Enf. Ref., 2016; IV(9): 3745.

16. FEITOSA MP, et al. Depressão: família, e seu papel no tratamento do paciente. Encontro de Psicologia, 2011; 14(21).

17. GUERRERO-MARTINEZ LF. Descrição da tentativa de suicídio como construto de violência na população infantil feminina. Rev. Fac. Nac. Saúde Pública, 2016; 34(3): 306-315.

18. HECK RM, et al. Ação dos profissionais de um centro de atenção psicossocial diante de usuários com tentativa e risco de suicídio. Texto contexto - enferm., 2012; 21(1): 26-33.

19. KITAGAWA T, et al. Adolescentes internados por tentativa de suicídio com agentes químicos: um estudo transversal. Semina: Ciências Biológicas e da Saúde, 2019; 40(1): 5-14.

20. KOCH DB, DE OLIVEIRA PRM. As políticas públicas para prevenção de suicídios. Revista Brasileira de Tecnologias Sociais, 2015; 2(2): 161-172.

21. KOVÁCS MJ, HWANG E. Suicídio por contágio e o papel das mídias de comunicação em massa. Revista M. Estudos sobre a morte, os mortos e o morrer, 2019; 4(7): 77-100.

22. LEITE FÁA, ALVES MAG. Violência gera violência: fatores de risco para a tentativa de suicídio entre adolescentes. Rev Med Minas Gerais, 2016; 26(8): 330-335.

23. LEMOS MFL, SALLES AMB. Algumas reflexões em torno do suicídio de crianças. Rev. Psicol. Unesp, assis, 2015; 14(1): 38-42.

24. LUXTON DD, et al. Social media and suicide: A public health perspective. American Journal of Public Health, 2012; 102(2): 195-200.

25. MALDONADO MT. Bullying e cyberbullying: o que fazemos com o que fazem conosco. São Paulo: Moderna, 2011. 
26. MDH. Ministério da Mulher, da Família e dos Direitos Humanos. O Suicídio e automutilação tratados sob a perspectiva da família e do sentido da vida / Ministério das Mulheres, da Família e dos Direitos Humanos; Brasília: 2019.53 p.

27. RESENDE C, et al. Depressão nos adolescentes: mito ou realidade? Nascer e Crescer, 2013; 22(3): 145-150.

28. RIBEIRO NM, et al. Análise da tendência temporal do suicídio e de sistemas de informações em saúde em relação às tentativas de suicídio. Texto contexto - enferm., 2018; 27(2): 2110016.

29. SALAZAR JMRS, OLIVEIRA MFS. Cultura, Memória e Literatura: a Infância em Obras Autobiográficas de Bartolomeu Campos de Queirós. Revista do Programa de Pós-Graduação em Literatura, 2015; 24(40): 187-208.

30. SOUSA GS, et al. Revisão de literatura sobre suicídio na infância. Ciênc. Saúde Coletiva, 2017; 22(9): $3099-3110$.

31. SOUZA VS, et al. Tentativas de suicídio e mortalidade por suicídio em um município no interior da Bahia. Jornal Brasileiro de Psiquiatria, 2011; 60(4): 294-300.

32. THAPAR A, et al. Depression in adolescence. Lancet., 2012; 379(9820): 1056-1067.

33. VIDAL CEL, GONTIJO ED. Tentativas de suicídio e o acolhimento nos serviços de urgência: a percepção de quem tenta. Cad. saúde colet., 2013; 21(2): 108-114.

34. WHO, 2014; WHO. World health organization. Preventing suicide: a global imperative. Geneva: who: 2014

35. ZELAYA DE MIGLIOIRSI L, et al. Abuso Infantil: Experiência Multidisciplinar Unidade de Saúde Mental Hospital Geral de Crianças de Acosta Nu. Pediatr. (Assunção), 2009; 36(3): 190-194.

36. ZELAYA DE MIGLIORISI L, et al. Tentativas de suicídio em crianças e adolescentes. Máscara de abuso infantil? Pediatr. (Assunção), 2012; 39(3): 167-172. 